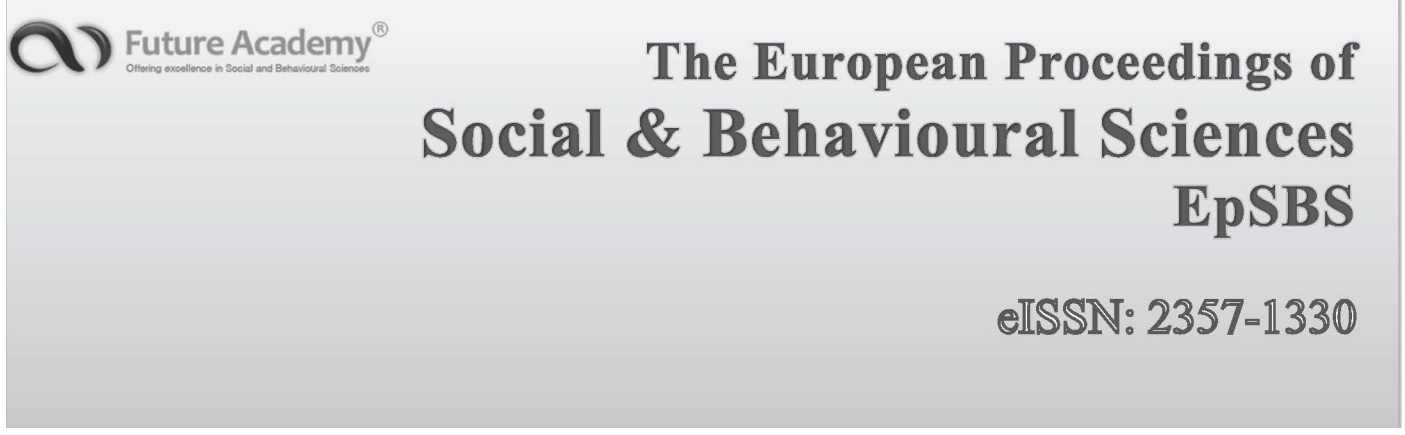

WELLSO 2016 - III International Scientific Symposium on Lifelong Wellbeing in the World

\title{
The Influence Of Ecological Culture On Ornithological Security At The Airport "Tomsk"
}

\author{
Kukhta $M,{ }^{\mathrm{a} *}$ Kukhta $\mathrm{A},{ }^{\mathrm{b}}$ Bolshakova $\mathrm{N}^{\mathrm{b}}$ \\ * Corresponding author: Kukhta M, eukuh@mail.tomsknet.ru \\ ${ }^{a}$ Kukhta $M^{*}$, Tomsk polytechnic university 634050, Lenina str., 30, Tomsk, Russia, \\ E-mail: eukuh@mail.tomsknet.ru 8-913-107-51-24 \\ ${ }^{b}$ Kukhta A, Bolshakova N, National Research Tomsk State University 634050, Lenina str. 36, Tomsk, Russia, \\ E-mail: artkuh@mail.tomsknet.ru, 8-913-877-96-36
}

\begin{abstract}
http://dx.doi.org/10.15405/epsbs.2017.01.54

The relation of directional distribution of bird population in winter on the airfield of the airport "Tomsk" with the presence of bird feeders on the territory of the adjoining residential complex were found out. It is shown that the concentration of feeding places of birds emerging near the feeders in the residential complex are kept mostly here as well as contribute birds redistribution from the territory of the airfield on its periphery thus contributing to reduce ornithological stress near the air strip. This distribution is characteristic not for all species but only for those who can use man-made elements of the environment to live in winter. Reporting to minimum of variety of birds at the airport these kinds are the majority. The formation of stable feeding clusters in the residential compound become by means of the high environmental culture of its inhabitants who help birds, providing them food in the unfavorable period of the year.
\end{abstract}

(C) 2017 Published by Future Academy www.FutureAcademy.org.uk

Keywords: Ornithological hazard, ornithological accidents prevention, gatherings of birds, birds feeders.

\section{Introduction}

Airline service is one of the safest means of transportation. The advanced control system virtually eliminates malfunctions of aerial vehicle (hereafter AV) due to internal reasons as a result are mainly external factors which are difficult to calculate the logical methods. One of the most significant is the collision of birds with aircraft. The relevance of this problem is that in fact in Russia in the last 10 years 544 aviation events between birds and AV were recorded. The situation is aggravated by the factor that the amount of air transportation is growing from one year to the next respectively collision risks are 
increasing. Thus in comparison with 2014 year the number of such aircraft accidents have increased in 1.4 times in 2015 (The Annex to the information on the fly operating safety, 2015). It is interesting to note that according to experts ' estimation the greatest risk of bird strike with the aircraft is about $45,8 \%$ and is observed at altitudes up to 100 metres (Kolesnichenko, 2007). In other words during periods of takeoff and landing therefore the greatest potential danger is represented by birds that are near airfields. It is necessary to pay priority attention on ornithological population near airports when planning for ornithological accidence prevention. Bird count in the territory of the airport "Tomsk" and on its environs show that the distribution of birds on the territory of the airfield in winter have an impact on the environmental literacy of the population of neighboring village which is expressed in the creation of regular refeeding points during the whole winter season.

\section{Materials and methods}

The study is based on the material of regular fixed-route accounting of birds in winter 12.01.2015 02.29.2016 years on the territory of airport "Tomsk" $(1.5 \mathrm{~km})$ and in its adjoining village also named "Airport" $(0.5 \mathrm{~km})$. Accounting was carried out in the morning from 8.00 till 10.00. During the study period 42 fixed-route accountings of birds with an average frequency three times a week were held, 1,485 birds belonging to 21 species were registered (Table 1). Such parameters as type, quantity, location of birds (flocks) towards the air strip (hereafter - the AS), flight path towards the airfield, the activities (sitting, flying, feeding) were recorded during accountings. For the convenience of position estimation of the birds ' location the airfield was divided into zones in accordance with the danger level of AV to the birds in these region(Kukhta, \&Moskvitin 2013). The accounting were carried out on the territory of municipal housing development of the village, here bird feeders were counted. During accounting cases of gatherings of birds around them, specific and quantitative composition were recorded. The proportion of food-filled bird feeders were recorded.

\section{Results and discussion}

From the standpoint of ornithological accidents prevention all species of birds should be considered potentially dangerous but objectively the real danger to the AV impose not all the kinds. Among the variety of airplane danger characteristics the fundamental morphological and ethological features are the dimension of birds and aggregating behavior. Flocks or gatherings can form almost all kinds of birds which is particularly unfavorable in the case of large or even medium sized species, but even a small-sized species (sparrows (Passer montanus L., Passer domesticus L.), swifts (Apuspacificus Lath., Apusapus L.) ) can be dangerous for the aircraft because of multiple collisions. Gatherings of birds are usually of directional nature, being stern (hooded crow (Corvuscornix L.), carrion crow (Corvuscorax L.), fieldfare (Turduspilaris L.), bullfinch (Pyrrhulapyrrhula L.), mealy redpoll (Carduelisflammea L.), goldfinch (Cardueliscarduelis L.), great tit (Parus major L.) and etc.), hidicolous (fieldfare, common starling (Sturnus vulgaris L.), rock pigeon(Columba livia Gmel.), barn swallow (Hirundorustica L.) and so on) or migrational (black kite (Milvusmigrans Bodd.), waxbird (Bombycillagarrulus L.), willow tit (Parusmontanus Bald.) and etc.). The causes of gatherings of birds can be influenced and controlled to some extent thereby change the bird hazard at the airfield of the airport. In the light of such 
circumstances according to the birds accounting the ecological culture of the inhabitants of the surrounding settlements affects on the bird hazard at the airfield of airport "Tomsk" in winter.

Under the environmental culture a human belief system is supposed which reflects its relationship with the natural environment (Reimers, \&Yablokov, 1982). Ecological culture of the inhabitants of the village "Airport" is manifested in an effort to help the birds in the most difficult for them winter season life cycle - they intensively fed them during the winter hanging out feeders on the territory of the village and on windows of houses which always attract birds. Anthropogenic areas are always attractive to the birds which find here suitable conditions for their living and foraging (Kukhta, \& Moskvitin, 2012, Kukhta, \& Moskvitin, 2014, Kukhta, \& Moskvitin, 2015)besides the latter is especially important in winter. Feeders help birds survive in unfavorable environmental conditions (Kukhta, \& Moskvitin, 2011, Kukhta, 2014) as a source of man-made food and hiding place. Besides that high-wrought feeders contribute aesthetic elevation of the area (Kukhta, 2015). In feeders the food are almost always present in which the most diverse food items: bacon, sunflower seeds, various cereals were recorded. Passersby or children often add feed that speaks to their indifferent attitude to the birds. Overall, there are up to 12 street feeders which are always full of food, about 10 window bird feeders in the village in winter as well as several grounds with dispersed feed near the heating pipes uncovered with snow attracts rock pigeon and fieldfare. During the winter they attract numerous flocks of house and field sparrow, up to 30 birds near the feeders kept bullfinch, great tit and etc. The neighborhood with forest area contributes to stay at the feeders virtually the entire spectrum of forest migrant birds.

Notably in winter there is the most visible link between ecologically-directed human activity and the number of birds on the airfield which is due to the peculiarities of the annual dynamics of the birds at the airport "Tomsk. During the year the species composition and birds distribution varies here. The highest ornithological activity is observed during periods of spring and autumn migrations. During this period the birds use the airfield not only for foraging but also for temporary shelter. In spring-summer period the territory attracts more birds and nesting possibility. Only in winter birds show first of all foraging strategy. During this period there is a minimal ornithological species composition, the majority of birds are found in the schooling variation (Figure 1). Due to the neighborhood of the airfield and settlement many birds species encountered in the territory of the latter where they form feed cluster whereby in spite of the smaller number of species occurring in the territory of the settlement their overall quantitative frequency of occurrence was just over (56 9\%) than on the airfield (43.1\%).

Table 1. Species composition of birds on the territory of the airfield of airport "Tomsk" in winter (2016)

\begin{tabular}{lllll}
\hline & Species & $\begin{array}{l}\text { Distribution in } \\
\text { winter time }\end{array}$ & $\begin{array}{l}\text { They form flocks or clusters } \\
\text { of more than } 5\end{array}$ & $\begin{array}{l}\text { Occurrence on } \\
\text { feeders }\end{array}$ \\
\hline 1 & Pica pica L. & widespread & - & + \\
2 & Corvuscornix L. & $\begin{array}{l}\text { occasionally } \\
\text { occurent }\end{array}$ & + & - \\
3 & Corvuscorax L. & widespread & - & - \\
4 & Nucifragacaryocatactes L. & scarse & - & + \\
\hline
\end{tabular}




\begin{tabular}{|c|c|c|c|c|}
\hline 6 & Bombycillagarrulus L. & scarse & + & + \\
\hline 7 & Dendrocopos major L. & $\begin{array}{l}\text { occasionally } \\
\text { occurent }\end{array}$ & - & + \\
\hline 8 & Sittaeuropaea L. & $\begin{array}{l}\text { occasionally } \\
\text { occurent }\end{array}$ & - & + \\
\hline 9 & Passer montanus L. & widespread & + & + \\
\hline $\begin{array}{l}1 \\
0\end{array}$ & Passer domesticus L. & widespread & + & + \\
\hline $\begin{array}{l}1 \\
1\end{array}$ & Carduelis flammea L. & $\begin{array}{l}\text { occasionally } \\
\text { occurent }\end{array}$ & + & - \\
\hline $\begin{array}{l}1 \\
2\end{array}$ & Loxia pytyopsittacus Bork. & $\begin{array}{l}\text { occasionally } \\
\text { occurent }\end{array}$ & + & - \\
\hline $\begin{array}{l}1 \\
3\end{array}$ & Carduelis carduelis L. & $\begin{array}{l}\text { occasionally } \\
\text { occurent }\end{array}$ & + & + \\
\hline $\begin{array}{l}1 \\
4\end{array}$ & Pyrrhula pyrrhula L. & widespread & + & + \\
\hline $\begin{array}{l}1 \\
5\end{array}$ & Parusmontanus Bald. & widespread & + & + \\
\hline $\begin{array}{l}1 \\
6\end{array}$ & Plectrophenax nivalis L. & scarse & + & - \\
\hline $\begin{array}{l}1 \\
7\end{array}$ & Parus major L. & scarse & + & + \\
\hline $\begin{array}{l}1 \\
8\end{array}$ & Parusater L. & $\begin{array}{l}\text { occasionally } \\
\text { occurent }\end{array}$ & + & + \\
\hline $\begin{array}{l}1 \\
9\end{array}$ & Aegithaloscaudatus L. & $\begin{array}{l}\text { occasionally } \\
\text { occurent }\end{array}$ & + & + \\
\hline $\begin{array}{l}2 \\
0\end{array}$ & Lyrurus tetrix L. & $\begin{array}{l}\text { occasionally } \\
\text { occurent }\end{array}$ & + & - \\
\hline $\begin{array}{l}2 \\
1\end{array}$ & Columba livia Gmel. & widespread & + & + \\
\hline
\end{tabular}

The balance of birds frequency on the airfield and in the village (Fig. 1) shows that for a number of species there is higher frequency on the territory of the village which is caused by the presence of the feeders, around which feeding flocks of birds are formed thus pulling birds from the territory of the airfield . It is indicative that 10 out of 11 species are led gregariousness in winter and two of them (fieldfare, rockpigeon) belong to medium dimension category that is a real threat to the aircraft. In this regard the role of village feeders appears significant in the diversion of these species from the territory of the airfield . 
http://dx.doi.org/10.15405/epsbs.2017.01.54

eISSN: 2357-1330 / Corresponding Author: Kukhta M.

Selection and peer-review under responsibility of the Organizing Committee of the conference

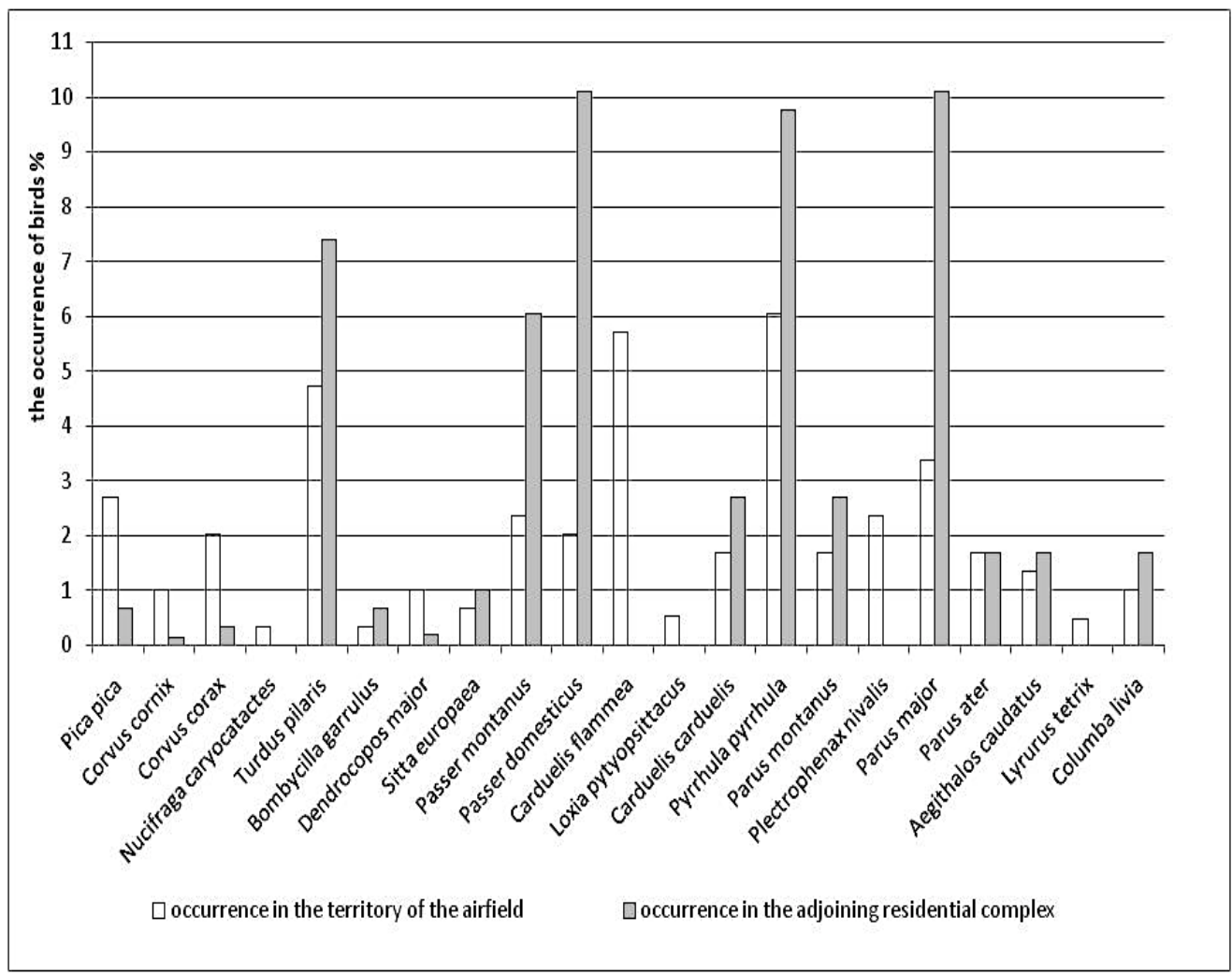

Fig. 1. Distribution of the occurrence of birds in winter 2015-2016.

Since the feed sources are always outside the airfield gatherings of birds are also found mainly on the border of the airfield or outside it and in most cases the main birds motion behavior is directed mainly along the boundaries of the airfield or beyond. The isolated cases of short-term birds departure towards the runway was recorded very rarely and always accompanied by the return of the birds back into the peripheral zone. As a result the feeders located on the territory of the village help to reduce the number of some species of birds near the airfield pulling them to the periphery of the airfield and out of its borders (Fig.2). 


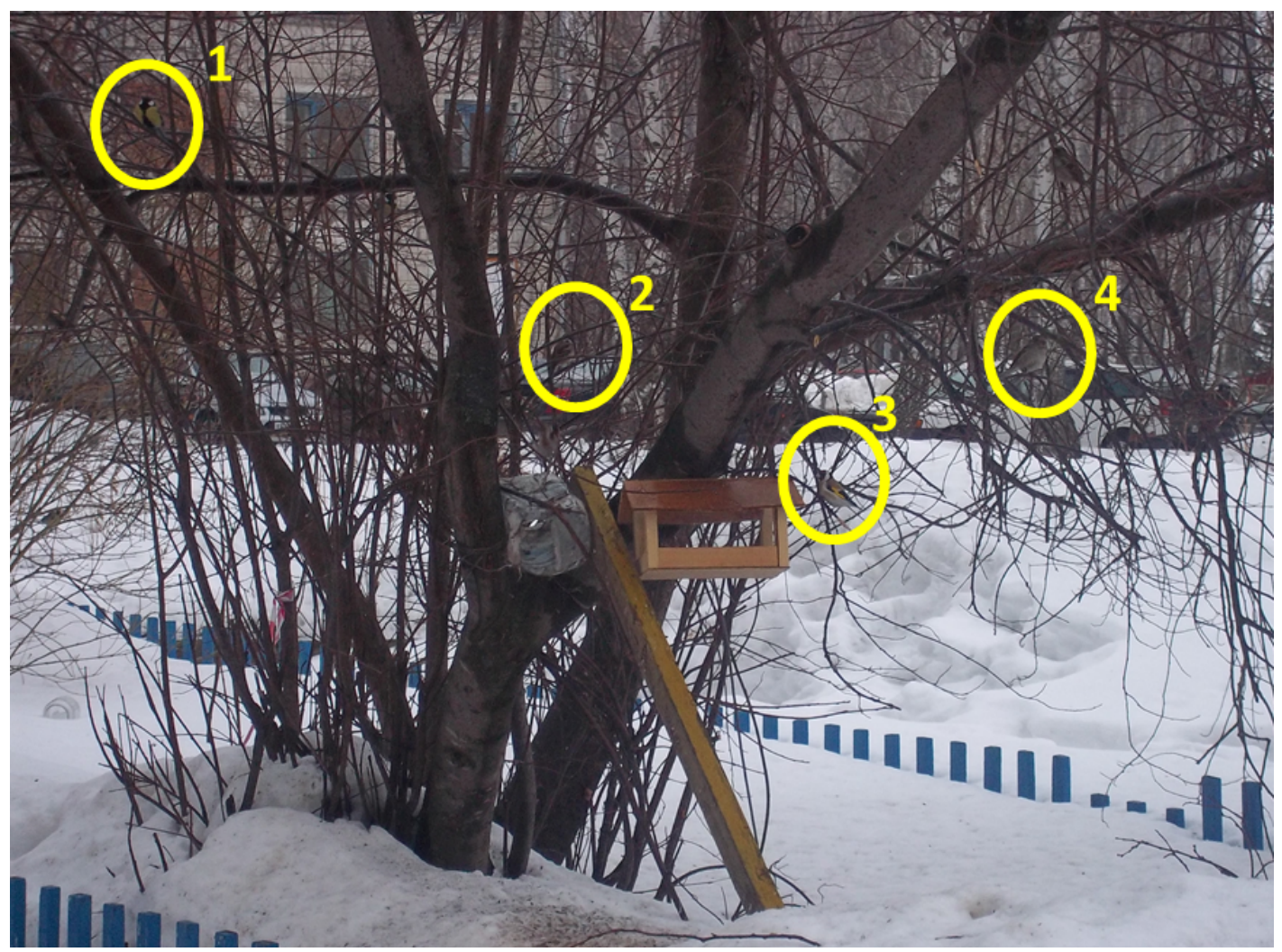

Fig. 2. The fragment of the multispecific gatherings of birds around the feeder: 1 - great tit, 2 - field sparrow, 3 - goldfinch 4 house sparrow.

Among the winter ornithological population of airport "Tomsk" not all species of birds are attracted by feeders some species prefer to use alternative feed. These birds most often is present at the airfield when searching food and stay for a long time near the runway or even on it, constantly moving and thereby creating a potentially dangerous situation for the aircraft. Thus the biggest occurrence of mealy redpoll and snow bunting were observed in the vicinity of the runway on the vast meadow areas where these species examined stand of grass sticking out of the snow while searching the seeds. On the territory of the village these species are not encountered. A similar pattern of occurrence was observed in crow who hunted on the airfield runway exclusively near the airfield or crossing it flying over. All crows met at the airfield were also on the runway or flying over it. Black cock is avoided by the man and during the winter period is held in the part of the airfield where it grows birch undergrowth, forming gatherings of up to 6 individuals and periodically crossing the airfield through the airfield. There were no such species as parrot crossbill and nutcracker near the feeders that due to the specifics of the feeding diet do not use feeders. These two species were encountered only in the territory of the airfield however they were only on its peripheral part in a forested area posed no hazard to the AV.

In general, the main winter birds are concentrated around the feeders while the number of species that use only airfield during winter period are small and only $28.9 \%$ of all occurring in winter and among these only 1 specie (black raven) is common while others are periodic or rare in occurrence. 


\section{Conclusion}

It was found that the distribution of winter ornithological population in airport "Tomsk" is unevenly. More birds are kept beyond the boundaries of the airfield in the territory adjoining to the village where they were attracted by numerous man-made feeders and other human food sources. Permanent fullness of the feeders by feed contributes to a constant birds attraction and indicates a high environmental culture of village population result in tendency to facilitate the bird life in difficult winter period. The residents of the village take care of birds that form steady feed clusters. All types of birds which are attracted and represent a real danger to the AV practically do not appear on AS. Similar distribution of birds across the territory happily affects on bird hazard of the airport. This distribution does not occur among species that do not use the feeders though the number of such species among the winter bird population of airport "Tomsk" Airport compose a smaller part.

\section{Acknowledgements}

This work was supported by grant RFFR 16-34-00751 mol_a, and as part of Competitiveness Enhancement Program of TSU (R\&D №8.1.25.2015).

\section{References}

Kolesnichenko, Y. (2007, December). Ornithological flight safety: problems and ways of their solution. Scientifictechnical magazine Flight Safety Problems, 12, 26-34.

Kukhta, A.E. (2014). Features of the design of structural elements bird feeders in a Tomsk. Modern Techniques and Technologies, 3, 251-252.

Kukhta, A.E. (2015). The relationship between form and function in the design of bird feeders in Tomsk. Proceedings of the Academy of Industrial art and design, 2, 17-21.

Kukhta, A.E., \& Moskvitin, S.S. (2011). Aesthetic and functional design features of bird feeders. Modern Techniques and Technologies, 3, 334-336.

Kukhta, A.E., \& Moskvitin, S.S. (2012, March). bird deaths on the roads in the vicinity of Tomsk. Bulletin of the Tomsk State University. Biology, 17(1), 85-94.

Kukhta, A.E., \& Moskvitin, S.S. (2014, June). Using technological elements of agricultural systems by birds in the vicinity of Tomsk. Bulletin of the Tuva State University. Natural and Agricultural Sciences, 2, 30-37.

Kukhta, A.E., \& Moskvitin, S.S. (2015, June). Using transmission lines by birds. Bulletin of the Tuva State University. Natural and Agricultural Sciences Issue, 2, 81-87.

Kukhta, A.E., Moskvitin, S.S., Gashkov, S.I., Nehoroshev, O.G., \& Tjuten'kov, O. Yu. (2013, November). The ornithological situation in the region of airport "Tomsk" in 2011. Proceedings of Tomsk State University. Biology Series, 284, 109-116.

Reimers, N. (1982). Glossary of terms and definitions related to the protection of wildlife. Moscow. M: Nauka. The Annex to the information on the fly operating safety (2015, September 12). Information on accidents and incidents associated with collisions between aircraft and birds and wild animals. Retrieved from http://www.favt.ru/public/materials/e/3/6/5/6/e36561df37c9b229ce722c69114bf192.pdf 